\section{Does intravenous immunoglobulin therapy prolong immunodeficiency in transient hypogammaglobulinemia of infancy?}

\author{
Lale Memmedova, Elif Azarsiz, \\ Neslihan Edeer Karaca, Guzide Aksu, \\ Necil Kutukculer
}

Department of Pediatric Immunology, Faculty of Medicine, Ege University, Izmir, Turkey

\section{Abstract}

Transient hypogammaglobulinemia of infancy (THI) is characterized by recurrent infections and one or more reduced serum immunoglobulin levels. Typically, THI patients recover spontaneously, mostly within 30-40 months of age, but sometimes recovery may be delayed until 5-6 years of age. The use of intravenous immunoglobulin (IVIg) as an alternative to antibiotic prophylaxis remains contraversial also in symptomatic THI patients. In fact, some authors believe that IVIg therapy may cause a delay in the maturation of the humoral immune system because of the interference from passively transfered antibodies. The aim of this study was to investigate the effect of IVIg replacement on recovery from immunodeficiency in THI patients and determine new parameters in order to include these patients in IVIg therapy groups. In this retrospective study, 43 patients (65\%) received IVIg replacement therapy while 23 patients (34.8\%) showed spontaneous normalization without IVIg. The percentages of patients who had more than six times the number of febrile infections in a year decreased from $91 \%$ to $21 \%$ in the group receiving IVIg treatment. At admission, before being recruited to IVIg therapy, serum immunoglobulin G (IgG) levels and antihemophilus B (Hib) antibody titers were found to be significantly low in cases who were selected for IVIg replacement. The percentages of patients who did not have protective levels of anti-Hib, anti-rubella or anti-rubeola-IgG were also significantly high in IVIg cases. There was no statistically significant difference in the age at which IgG levels normalized between the IVIg and the non-IVIg group. Patients in the IVIg group and non-IVIg group reached normal IgG levels at the age of $42.9 \pm 22.0$ and $40.7 \pm 19.8$ months, respectively. In conclusion, IVIg infusions do not cause a delay in the maturation of the immune system in THI patients. Besides the well-established criteria, very low and non-protective specific antibody responses against previously applied vaccines are important factors to consider when selecting patients for IVIg therapy.

\section{Introduction}

Transient hypogammaglobulinemia of infancy (THI) is a common primary humoral immunodeficiency characterized by a transient immunoglobulin production defect which resolves by 30-40 months of life. However, in rare cases, the period of recovery can extend to up to five years.1,2 In the blood samples of these patients, initial serum immunoglobulin G (IgG) levels are lower than two standard deviations below the mean for age-specific reference values. They then begin to increase and are followed by normal values. The diagnosis of THI can be made retrospectively. 3,4 THI patients frequently have recurrent infections and are sometimes asymptomatic. 2,5

Transient hypogammaglobulinemia of infancy is not considered to be a disease that justifies substitutive intravenous immunoglobulin (IVIg) therapy and thus the use of IVIg as an alternative to antibiotic prophylaxis remains controversial. Little is known about whether the immunoglobulin replacement treatment has a negative effect on the maturation of the patient's immune system. In a paper concerning early treatment with IVIg, Buckley and Durham raised concerns related to the risk of interference with and delay of endogenous specific antibody production. 6 However, 10 $20 \%$ of THI patients who had severe and recurrent infections and who, therefore, needed hospitalization were given IVIg by their physicians and pediatric immunologists. ${ }^{7}$

The aim of this study was to investigate the effect of IVIg therapy on recovery from immunodeficiency in THI patients, and to monitor and compare the clinical and laboratory characteristics of those THI patients selected and those not selected for IVIg treatment.

\section{Materials and Methods}

\section{Study design and patients' characteristics}

The following criteria were used to diagnose THI patients at the Ege University Faculty of Medicine, Department of Pediatric Immunology, Izmir, Turkey: i) at admission IgG serum levels less than 2 SDs of age-related normal values; ii) over $2 \%$ circulating $B$ cells; iii) exclusion of known causes of hypogammaglobulinemia such as drugs, genetic disorders, chromosomal abnormalities, infectious diseases, neoplasias, systemic disorders and
Correspondence: Elif Azarsiz, Department of Pediatrics, Faculty of Medicine, Ege University, 35100 Bornova, Izmir, Turkey.

Tel. +90.232 .3901070 .

E-mail: elif.azarsiz@ege.edu.tr

Key words: intravenous immunoglobulin, specific antibody response, transient hypogammaglobulinemia of infancy.

Contributions: the authors contributed equally.

Conflict of interests: the authors declare no potential conflict of interests.

Received for publication: 2 May 2013.

Revision received: 4 June 2013.

Accepted for publication: 8 July 2013.

This work is licensed under a Creative Commons Attribution NonCommercial 3.0 License (CC BYNC 3.0).

(O)Copyright L. Memmedova et al., 2013

Licensee PAGEPress, Italy

Pediatric Reports 2013; 5:e14

doi:10.4081/pr.2013.e14

prematurity. Sixty-six patients under the age of 48 months whose IgG reached age-related normal levels during follow up were included in the study and their data were evaluated retrospectively. Of these patients, 43 received IVIg (IVIg group) and 23 received prophylactic antibiotics or did not receive any medication at all (Non-IVIg group) before normalization of their immunoglobulin levels.

The THI patients who satisfied the following criteria received IVIg therapy at the Ege University: i) patients who had six times or more upper respiratory infections and/or otitis media, or two or more sinusitis, or one or more pneumonia events in one year; ii) patients who used antibiotics more than six times a year; iii) patients who needed intramuscular or intravenous injection for the recovery of infection; iv) patients who had severe infections such as menengitis or sepsis. Patients fulfilling these criteria received $400-500 \mathrm{mg} / \mathrm{kg}$ IVIg at 6-8 week intervals and were all monitored for IgG-M-A levels just before IVIg replacement. In addition, some of the following criteria were applied for stopping IVIg therapy: i) steady increase in serum immunoglobulin concentrations; ii) clinical recovery findings (such as $50 \%$ decrease in frequency of infections); iii) normalization of IgG at least two months after last IVIg therapy (just before scheduled treatment). The IgG level obtained before IVIg replacement was suggested to be the patients' own because of the approximately 3-week half-life of IgG. An evaluation sheet was used to summarize the patients' characteristics including name, gender, date of birth, 
age at onset of symptoms, age at admission. Clinical characteristics included type and frequency of infections, and total duration of IVIg therapy. Laboratory data included whole blood count, serum immunoglobulin concentrations, absolute counts and percentages of lymphocyte subsets, serum specific antibody responses against tetanus, hemophilus influenza type B, hepatitis $\mathrm{B}$, rubella, rubeola and mumps, and age at normalization of serum immunoglobulins, especially serum IgG. In the IVIg group, these values were all obtained before IVIg therapy except for immunoglobulin levels that were periodically monitored. Approval from the Institutional Ethics Committee and informed written consent for participation was obtained in all cases. All patients with THI received instructions for home care during follow up.

The following laboratory methods had been used to evaluate THI patients: whole blood count, leukocyte counts, absolute neutrophil and lymphocyte counts, and relative ratio, performed with a hemocounter (Cell-Dyn 3700, Abbott Diagnostics, Abbott Park, Illinois, USA).

Serum immunoglobulins (IgG, IgA, IgM) were evaluated by nephelometry (Dade
Behring BNII, Siemens, Germany) and compared with age-related normal levels. ${ }^{8}$ Absolute counts and percentages of lymphocyte subsets (CD3+T, CD19+B, CD16+56+NK, CD3+CD4+ Thelper and $\mathrm{CD} 3+\mathrm{CD} 8+$ cytotoxic cells) were investigated by 4-color flow cytometry (FACSCalibur, Becton-Dickinson, USA).

Serum anti-tetanus IgG, anti-hemophilus influenza type b IgG, anti-rubella IgG, antirubeola IgG, and anti-mumps IgG levels were investigated using commercial ELISA kits.

Table 1. Demographic and clinical characteristics and laboratory data of transient hypogammaglobulinemia of pediatric patients who were treated and were not treated with intravenous immunoglobulin. In the intravenous immunoglobulin group, antibody levels were determined before intravenous immunoglobulin therapy.

\begin{tabular}{|c|c|c|c|}
\hline Demographic and clinical characteristics & IVIg group & Non-IVIg group & $\mathbf{P}$ \\
\hline Patients, n (\%) & $43(65)$ & $23(35)$ & \\
\hline Age at diagnosis (months) & $13.4 \pm 9.5$ & $17.0 \pm 9.2$ & 0.091 \\
\hline $\begin{array}{l}\text { Gender } \\
\text { Female } \\
\text { Male }\end{array}$ & $\begin{array}{c}8(18) \\
35(82)\end{array}$ & $\begin{array}{c}3(13) \\
20(87)\end{array}$ & \\
\hline $\begin{array}{l}\text { Frequency of infection, } n(\%) \\
<6 \text { per year } \\
6-12 \text { per year }\end{array}$ & $\begin{array}{c}4(9) \\
39(91)\end{array}$ & $\begin{array}{l}16(70) \\
7(30)\end{array}$ & \\
\hline $\begin{array}{l}\text { Infection type, } n(\%) \\
\text { Upper respiratory tract infection } \\
\text { Lower respiratory tract infection } \\
\text { Upper and lower respiratory tract infection } \\
\text { Urinary tract infection } \\
\text { Upper respiratory and urinary tract infection } \\
\text { Acute gastroenteritis } \\
\text { Acute osteomyelitis } \\
\text { Upper respiratory tract infection, acute gastroenteritis } \\
\text { Lower respiratory tract infection, acute gastroenteritis } \\
\text { Urinary tract infection, acute osteomyelitis }\end{array}$ & $\begin{array}{c}9(25.7) \\
10(28.6) \\
5(14.3) \\
2(5.7) \\
3(8.6) \\
1(2.9) \\
1(2.9) \\
2(5.7) \\
1(2.9) \\
1(2.9)\end{array}$ & $\begin{array}{l}11(47.8) \\
4(17.4) \\
2(8.7) \\
1(4.3) \\
2(8.7) \\
1(4.3) \\
2(8.7)\end{array}$ & \\
\hline $\begin{array}{l}\text { Laboratory (mean } \pm \text { SD) } \\
\text { Leukocyte count }(103 / \mu \mathrm{L}) \\
\text { Absolute lymphocyte/mm3 } \\
\text { Initial IgG (mg/dL) } \\
\text { 6-8 months (411.1-826.9)* } \\
\text { 9-12 months (533.9-896.1)* } \\
\text { 13-24 months (600.1-999.5)* } \\
\text { 25-36 months (640.1-1056.9)* } \\
\text { Initial IgA (mg/dL) } \\
\text { Initial IgM (mg/dL) } \\
\text { CD3+ T cells, \% } \\
\text { CD3+4+ T-helper cells, \% } \\
\text { CD3+CD8+ T-cytotoxic cells, \% } \\
\text { CD19+ B cells, \% } \\
\text { CD3-CD16+CD56+ natural killer cells, \% } \\
\text { CD3+HLA DR+ active T cells, \% } \\
\text { Anti-tetanus antibody (IU/mL) } \\
\text { Anti-hemophilus influenza B antibody (IU/mL) }\end{array}$ & $\begin{array}{c}10.8 \pm 3.67 \\
5778.6 \pm 216 \\
1.0 \\
371.7 \pm 134.3 \\
336.6 \pm 181.6 \\
371.1 \pm 86.2 \\
438.4 \pm 95.7 \\
370.8 \pm 132.2 \\
36.1 \pm 37.9 \\
58.4 \pm 26.2 \\
65.2 \pm 11.2 \\
40.1 \pm 10.7 \\
20.5 \pm 5.03 \\
22.3 \pm 6.40 \\
6.60 \pm 3.30 \\
8.48 \pm 8.39 \\
1.65 \pm 3.00 \\
0.32 \pm 0.16\end{array}$ & $\begin{array}{c}11.0 \pm 3.56 \\
4075.7 \pm 2293.9 \\
438.6 \pm 176.1 \\
176.0 \pm 0 \\
422.2 \pm 141.8 \\
509.2 \pm 141.9 \\
495.5 \pm 671.7 \\
44.9 \pm 43.3 \\
79.1 \pm 62.0 \\
63.2 \pm 9.99 \\
40.7 \pm 10.02 \\
20.7 \pm 6.60 \\
20.6 \pm 7.57 \\
6.99 \pm 4.38 \\
9.20 \pm 9.66 \\
1.15 \pm 0.76 \\
2.97 \pm 2.46\end{array}$ & $\begin{array}{l}0.225 \\
0.194 \\
0.261 \\
0.791 \\
0.615 \\
0.695 \\
0.831 \\
0.865 \\
0.315 \\
0.009\end{array}$ \\
\hline $\begin{array}{l}\text { Protective IgG antibody, n/total (\%) } \\
\text { Anti-tetanus antibody } \\
\text { Anti-Hib IgG antibody } \\
\text { Anti-Hbs antibody } \\
\text { Anti-rubella antibody } \\
\text { Anti-rubeola antibody } \\
\text { Anti-mumps antibody }\end{array}$ & $\begin{array}{c}11 / 15(73.3) \\
11 / 12(91.7) \\
33 / 37(89.2) \\
4 / 9(44.4) \\
5 / 11(45.5) \\
5 / 11(45.5)\end{array}$ & $\begin{array}{c}13 / 15(86.7) \\
12 / 12(100) \\
16 / 20(80.0) \\
13 / 16(81.3) \\
13 / 16(81.3) \\
7 / 13(53.8)\end{array}$ & $\begin{array}{l}0.315 \\
0.009 \\
0.345 \\
0.044 \\
0.050 \\
0.688\end{array}$ \\
\hline Age of normalization of IgG levels (months) & $42.9 \pm 22.0$ & $40.7 \pm 19.8$ & 0.812 \\
\hline
\end{tabular}

IVIg, intravenous immunoglobulin; SD, standard deviation; Ig, immunoglobulin; Hib, anti-hemophilus B. *Age specific reference ranges for IgG. 


\section{Statistical analysis}

Statistical analyses were performed using SPSS (Windows version 17.0, SPSS Inc., Chicago, IL, USA). $\chi^{2}$ and Mann Whitney U tests were also used. $\mathrm{P}<0.05$ was considered significant.

\section{Results}

A total of 66 THI patients (11 female, 17\%; 55 male, 83\%) 6-48 months of age were included in this study. Mean age at admission of all patients was $14.5 \pm 9.5$ months. Sixty percent of patients had infections 6-12 times per year and the most frequent infection types were upper respiratory tract infections $(\mathrm{n}=20,34.5 \%)$, lower respiratory tract infections $(\mathrm{n}=14,24 \%)$, and urinary tract infections $(\mathrm{n}=8,13.8 \%)$.

Forty-three patients $(65 \%)$ received IVIg replacement therapy while 23 patients (34.8\%) showed spontaneous normalization without IVIg. IVIg therapy was started at the age of $14.3 \pm 8.8$ months and ended at the age of $25.2 \pm 12.7$ months; mean duration with IVIg therapy was, therefore, $14.6 \pm 9.0$ months. Demographic and clinical characteristics and laboratory data of patients who were treated and who were not treated with IVIg are summarized in Table 1. In the non-IVIg group and IVIg group, $30 \%$ and $91 \%$ of patients had infections more than six times per year, respectively. In the IVIg group, mean age at diagnosis was $13.4 \pm 9.5$ months which is lower than the non-IVIg group. In the IVIg group, the percentage of frequent infections (6-12 times per year) decreased from $91 \%$ to $21 \%$ after IVIg therapy (Table 2). No statistically significant difference was found either before or after therapy for infection type $(\mathrm{P}=0.129)$ or frequency $(\mathrm{P}=0.446)$ (Table 2). On the other hand, duration of follow up for each patient was divided into two periods in the non-IVIg group: initial period and recovery period. The total number of infections in the initial period in the nonIVIG group was 47 while this was 42 in the second period. The total numbers of infections in the non-IVIg group decreased slightly but this was not significantly different $(P>0.05)$.

Laboratory data did not show any significant difference between the IVIg and the non-IVIg groups except for initial IgG levels $(\mathrm{P}=0.048)$ and anti-hemophilus influenza $\mathrm{B}$ antibody levels $(\mathrm{P}=0.009)$ which were lower in the IVIg treated group (Table 1).

The percentage of patients who had protective specific antibody response to hemophilus influenza type B was significantly lower in the IVIg group (91.7\%) compared to the non-IVIg group (100\%) $(\mathrm{P}=0.009)$ (Table 1) although all patients had all doses of hemophilus influenza type B. Anti-rubella and anti-rubeola responses also showed significant differences $(\mathrm{P}=0.044$ and $\mathrm{P}=0.050$, respectively) and they were very low in the IVIg group, e.g. $44.4 \%$ for rubella and $45.5 \%$ for rubeola.

In the group of patients who did not receive IVIg therapy, serum IgG levels increased to age-related normal levels at the age of $40.7 \pm 19.8$ months. On the other hand, age of normalization of IgG levels in THI patients who received IVIg was $42.9 \pm 22.0$ months and there was no statistical significant difference between the two groups $(\mathrm{P}=0.812)$ (Table 1).

\section{Discussion}

Transient hypogammaglobulinemia of infancy is a common primary humoral immunodeficiency disorder characterized by a delay in maturation in the normal production of immunoglobulin. It usually resolves by the age of 30-40 months. 1,2,9 Prevalance of primary immunodeficiencies for Turkish patients is 30.5 per 100,000 (18.8 per 100,000 in Ege University records) in the European Society for Immune Deficiencies (ESID) database and two-thirds of them are humoral immunodeficiencies. 10 THI is the most common disorder with a prevalance of 7.01 per 100,000 in registered patients.

In the report by Walker et al.,11 the mean age of symptoms of THI patients was ten months (range 2-24) and they also had lower IgA and IgM concentrations in addition to IgG. The age of our study population ranged between 6-48 months and the mean age of all patients at admission was $14.5 \pm 9.5$ months. There was no difference in $\operatorname{IgA}$ and $\operatorname{Ig} M$ concentrations according to age-related normal levels.

In the literature, THI patients show male dominance (Walker et al. 74\%11; Kidon et al. $75 \% 12$; Dalal et al. $69 \% 13$ ). A total of $69.8 \%$ of Turkish THI patients recorded on the ESID database and $83 \%$ ( 55 of 66 ) of our study patients were also male. ${ }^{10}$ Whelan et al. ${ }^{14}$ reported that low IgG concentrations in females took longer to normalize than males. We did not make a similar comparison in our study as the majority of patients were male.

Recurrent infections are the most common reasons for morbidity and hospitalization, and are frequently related to humoral immunodeficiencies. Physicians often prefer antibiotic prophylaxis or follow up without medication, but some authors proposed that the lack of specific antibodies should be used in the decision making process when treating THI patients with IVIg.7,15 Duse et al. ${ }^{16}$ suggested that IVIg should be used in severely symptomatic children in order to stop the vicious circle of infection-immunodeficiency. They treated 13 severely symptomatic THI children with IVIg (400 $\mathrm{mg} / \mathrm{kg} /$ every 3 weeks) for a period of three months and followed them for 1-3 years. Their patients had respiratory tract infections and showed a 10 -fold decrease in the frequency of infections after IVIg therapy. They speculated that IVIg was more effective than antibiotics in treating viral infections in infants by means of its antiviral antibody contents.

In our study group, 43 of approximately 400 THI patients who underwent follow up in our outpatients' clinic received IVIg. This rate (10.7\%) corresponds with the profile of our hospital as a tertiary care center. The pharmacokinetics of IVIg shows considerable intraand interpopulation variability among patients with normal immunoglobulin levels, patients with primary immunodeficiency diseases, bone marrow transplant recipients, patients with immune deficiency due to chronic lymphocytic leukemia, or in some other diseases. ${ }^{17}$ In different pharmacokinetic studies in pediatric primary immunodeficiency patients, IgG half-life was found to be between $30.9 \pm 11.3$ and $50.8 \pm 30.3$ days. $18-20$ Our patients received IVIg therapy at 6-8 week intervals because of some social and economical problems, and the variable half-life of IVIg among patients. In our previous study, we had declared frequency of upper respiratory tract infections as $76 \%$ in patients with IgA and/or IgG subgroup deficiency. ${ }^{21}$ Similar to our results, in the reports by Kiliç and Kidon et al. the Authors had found high percentages of infecti-

Table 2. Frequency and type of infections in intravenous immunoglobulin-treated transient hypogammaglobulinemia patients $(n=43)$.

\begin{tabular}{|c|c|c|c|c|c|}
\hline & Befor & erapy & After & hera & $\mathbf{P}$ \\
\hline & N. & $\%$ & N. & $\%$ & \\
\hline Frequency of infection & & & & & \\
\hline$<6$ per year & 4 & 9 & 31 & 72 & 0.446 \\
\hline 6-12 per year & 39 & 91 & 9 & 21 & \\
\hline Infection type & & & & & 0.129 \\
\hline Upper respiratory tract infection & 11 & 26 & 33 & 75 & \\
\hline Lower respiratory tract infection & 12 & 28 & 2 & 5 & \\
\hline Upper and lower respiratory tract infection & 6 & 14 & 5 & 11 & \\
\hline Urinary tract infection & 6 & 14 & - & - & \\
\hline Others (acute gastroenteritis, osteomyelitis) & 7 & 16 & - & - & \\
\hline
\end{tabular}

IVlg, intravenous immunoglobulin. 
ons ( $70 \%$ and $88 \%$, respectively).2,12

A total of $47.5 \%$ patients had 6-12 infections per year in the study by Karaca et al. ${ }^{9}$ This rate was approximately $30 \%(n=16)$ in our non-IVIg group. In the other group, this rate decreased from $91 \%$ to $21 \%$ after IVIg therapy (Table 2). A decline in the frequency of infections was remarkable after IVIg therapy but the difference was not statistically significant $(\mathrm{P}=0.446)$. It was observed that IVIg therapy led to a decrease in severe infections (such as lower respiratory tract infections) from $28 \%$ to $5 \%$. The increased percentage of upper respiratory infection after IVIg is due to a decrease in the general rate of infections and the two are, therefore, related.

In literature, lymphocyte subset percentages in THI patients are generally reported within age-related normal ranges. $2,14,22,23$ Similarly, we had found both the initial lymphocyte subset percentages and their absolute counts to be in the normal range in our present and in our previous studies. ${ }^{9}$ In the report by Artac et al., ${ }^{24}$ T-cell, B-cell and NK-cell counts were also within normal ranges. Percentages of CD19 in B cells were normal, but CD19 median fluorescence intensity was lower in THI patients than in the control group. CD19+27+ memory B-cell percentages were also low in the study by Artac et al. n contrast with our reports of normal values $(3.4 \pm 1.4 \%)$ in one of our previous studies. ${ }^{9}$ Moschese et al..$^{25}$ also reported a lower frequency of memory B cells in patients over the age of 24 months. The reports by Artac and Moschese suggest that the evaluation of memory B cells can be used to predict the outcome of the disease and facilitate differential diagnosis. We did not evaluate memory cells in our present study group.

In addition to serum IgG levels, the number of patients with protective specific antibody response to hemophilus influenza $B$ was significantly lower in the IVIg group (91.7\%) in comparison to the non-IVIg group (100\%) $(\mathrm{P}=0.009)$ (Table 1). Serum antibody levels against hemophilus influenza type $B$ were also significantly low. The percentages of protective anti-rubella and anti-rubeola responses were also very low in the IVIg group. Infants are immunized with MMR vaccine at the age of one year in Turkey. The patients who did not present antibodies against these antigens were checked again; they were all over one year of age and they had all been immunized. These findings provide another reason for selecting which THI patients should receive IVIg.

Transient hypogammaglobulinemia of infancy is characterized by IgG maturation defect. Most of the patients' IgG normalize at around 36 months of age but recovery may sometimes be longer. ${ }^{13,14,26-28}$ Different studies showed that IgG normalized at 30-40 months in $76 \%$ of patients, ${ }^{2}$ at five years in $80 \%$ of pati- ents, and at ten years in $70 \%$ of patients. ${ }^{13,28}$ Keles et al. ${ }^{29}$ reported that only $25 \%$ of patients had complete resolution of their immunoglobulin abnormalities before three years of age and mean recovery age was $68.8 \pm 36.5$ months. On the other hand, some authors believe that periodic administration of IVIg therapy may cause a delay in the maturation of the immune system. In our study, it was clearly observed that there was no statistical difference between the ages of IVIg treated and non-IVIg treated THI patients whose IgG levels achieved normal values, although the mean duration of IVIg therapy was more than one year.

\section{Conclusions}

We can conclude that use of IVIg therapy in selected THI patients with severe and recurrent infections might be prefered on account of the better clinical improvement achieved. In most pediatric immunology centers, approximately $10 \%$ of THI patients receive IVIg therapy. In addition to other well-known parameters, the physicians can easily decide if such therapy is appropriate if the patient has very low IgG levels $(371 \pm 134 \mathrm{mg} / \mathrm{dL})$ and inadequate or non-protective specific antibody responses to routine vaccines. Infused IVIg does not prolong immunodeficiency in THI patients.

\section{References}

1. Dalal I, Roifman CM. Hypogammaglobulinemia of infancy. Immunol Allergy Clin North Am 2001;21: 129-39.

2. Kılıc S, Tezcan İ, Sanal 0, et al. Transient hypogammaglobulinemia of infancy: clinical and immunologic features of 40 new cases. Pediatr Int 2000;42:647-50.

3. McGeady SJ. Transient hypogammaglobulinemia of infancy: need to reconsider name and definition. J Pediatr 1987;110: 47-3.

4. Tiller TL, Buckley RH. Transient hypogammaglobulinemia of infancy: review of the literature, clinical and immunologic features of 11 new cases, and long-term followup. J Pediatr 1978;92:347.

5. Wilson CB, Lewis DB, Penix LA. The physiologic immunodeficiency of immaturity. In: Stiehm ER, ed. Immunologic disorders in infants and children. Philadelphia: WB Saunders; 1996. p. 253.

6. Buckley RH, Durham NC. Primary immunodeficiency or not? Making the correct diagnosis. J Allergy Clin Immunol 2006; 117:756-8.

7. Bonilla FA, Bernstein IL, Khan DA, et al. Practice parameter for the diagnosis and management of primary immunodeficiency. Ann Allergy Asthma Immunol 2005;94:1-63.

8. Aksu G, Genel F, Koturoglu G, et al. Serum immunoglobulin (IgG, IgM, IgA) and $\operatorname{Ig} \mathrm{G}$ subclass concentrations in healthy children: a study using nephelometric technique. Turk J Pediatr 2006;48:19-24.

9. Karaca NE, Aksu G, Gulez N, et al. New laboratory findings in Turkish patients with transient hypogammaglobulinemia of infancy. Iran J Allergy Asthma Immunol 2010;9:237-43.

10. Kiliç SS, Ozel M, Hafızoglu D, et al. The prevalances and patient characteristics of primary immunodeficiency diseases in Turkey-two centers study. J Clin Immunol 2013;33:74-83.

11. Walker AM, Kemp AS, Hill DJ, Shelton MJ. Features of hypogammaglobulinemia in infants screened for immunological abnormalities. Arch Dis Child 1994;70:183.

12. Kidon MI, Handzel ZT, Schwartz R, et al. Symptomatic hypogammaglobulinemia in infancy and childhood - clinical outcome and in vitro immune responses. BMC Fam Pract 2004;21:23.

13. Dalal İ, Reid B, Nisbet-Brown E, Roifman CM. The outcome of patients with hypogammaglobulinemia in infancy and early childhood. J Pediatr 1998;133-144.

14. Whelan MA, Hwan WH, Beausoleil J, et al. Infants presenting with recurrent infections and low immunoglobulins: characterisctics and analysis of normalization. $\mathrm{J}$ Clin Immunol 2006;26:7-11.

15. Dorsey MJ, Orange JS. Impaired specific antibody response and increased B-cell population in transient hypogammaglobulinemia of infancy. Ann Allergy Asthma Immunol 2006;97:590-5.

16. Duse M, Iacobini M, Lenoardi L, et al. Transient hypogammaglobulinemia of infancy: intravenous immunoglobulin as first line therapy. Int $\mathbf{J}$ Immunopathol Pharmacol 2010;23:307-11.

17. Koleba T, Ensom MH. Pharmacokinetics of intravenous immunoglobulin: a systematic review. Pharmacotherapy 2006;26:813-27.

18. van der Meer JW, van Beem RT, Robak T, et al. Efficacy and safety of a nanofiltered liquid intravenous immunoglobulin product in patients with primary immunodeficiency and idiopathic thrombocytopenic purpura. Vox Sang 2011;101:138-46.

19. Kreuz W, Erdös M, Rossi P, et al. A multicentre study of efficacy and safety of Intratect ${ }^{\circledR}$, a novel intravenous immunoglobulin preparation. Clin Exp Immunol 2010;161:512-7.

20. Wasserman RL, Church JA, Peter HH, et al. Pharmacokinetics of a new $10 \%$ intravenous immunoglobulin in patients receiving replacement therapy for primary immuno- 


\section{Article}

deficiency. Eur J Pharm Sci 2009;37:272-8.

21. Kutukculer N, Edeer Karaca N, Demircioglu 0, Aksu G. Increases in serum immunoglobulins to age related normal levels in children with IgA and/or IgG subclass deficiency. Pediatr Allergy Immunol 2007;8:167-73.

22. Dogu F, Ikinciogullari A, Babacan E. Transient hypogammaglobulinemia of infancy and early childhood: outcome of 30 cases. Turk J Pediatr 2004;46:120-4.

23. Ikinciogulları A, Kendirli T, Dogu F, et al. Peripheral blood lymphocyte subsets in healthy Turkish children. Turk J Pediatr
2004;46:125-30.

24. Artac H, Kara R, Gokturk B, Reisli I. Reduced CD19 expression and decreased memory B cell numbers in transient hypogammaglobulinemia of infancy. Clin Exp Med 2012 July 21 [Epub ahead of print].

25. Moschese V, Carsetti R, Graziani S, et al. Memory B cell subsets as a predictive marker of outcome in hypogammaglobulinemia during infancy. J Allergy Clin Immunol 2007;120:474-6.

26. Iseki M, Heiner DC. Immunodeficiency disorders. Pediatr Rev 1993;14:226.

27. Kutukculer N, Gulez N. The outcome of patients with unclassified hypogammaglobulinemia in early childhood. Pediatr Allergy Immunol 2009;20:693-8.

28. Kanariou M, Petridou E, Liatsis M, et al. Age patterns of immunoglobulins G, A \& M in healthy children and the influence of breast feeding and vaccination status. Pediatr Allergy Immunol 1995;6:24-9.

29. Keles S, Artac H, Kara R, et al. Transient hypogammaglobulinemia and unclassified hypogammaglobulinemia: similarities and differences. Pediatr Allergy Immunol 2010; 21:843. 